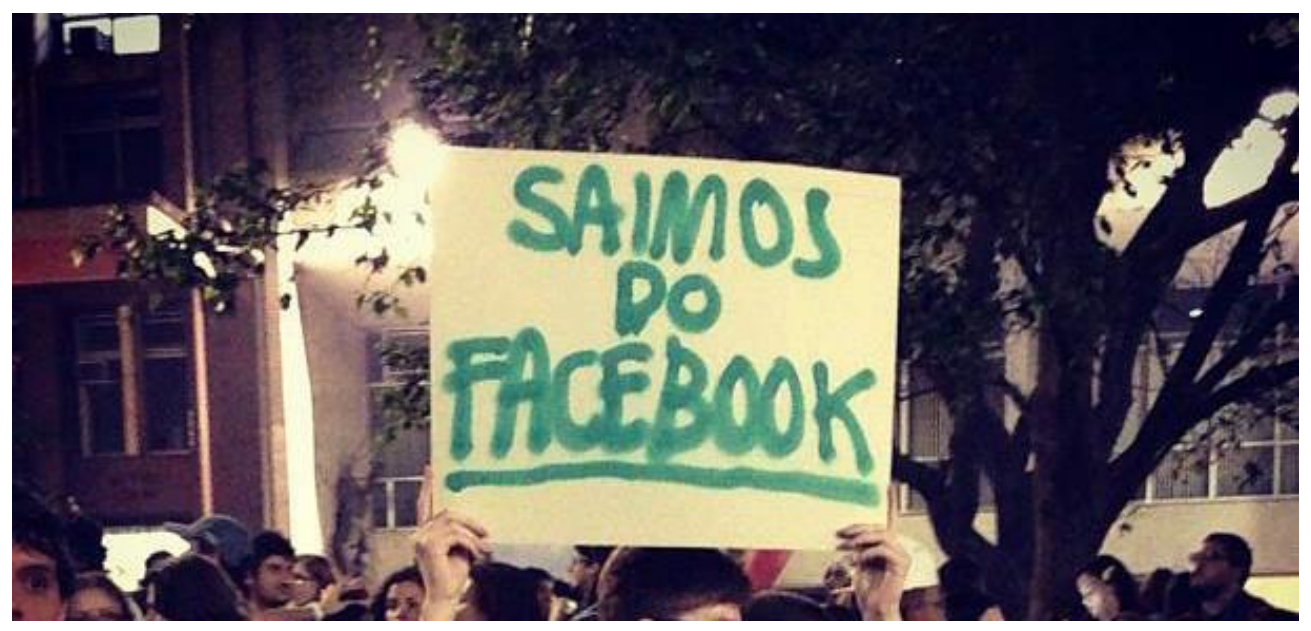

\title{
Das infovias às ruas: O Facebook e as manifestações sociais na perspectiva da teoria do caos/complexidade ${ }^{*}$
}

From the infovias to the streets: The Facebook and the social manifestations from the perspective of chaos/complexity theories

\author{
Valdir Silva ${ }^{1}$ \\ Rodrigo de Santana Silva ${ }^{2}$
}

Resumo: As redes sociais eletrônicas são constitutivas das práticas sociais contemporâneas e se configuram em importantes espaços de significação histórica, cultural, ideológica, psicológica, linguística, estética para os sujeitos que nelas se inscrevem. As redes são espaços complexos e dinâmicos e dependentes das práticas de linguagem em todas as suas modalidades e plasticidade. Assim, para dar visibilidade a esses funcionamentos e feitos, tomamos para análise e reflexões, as materialidades discursivas que emergiram das manifestações de junho de 2013 no Brasil, no contexto do Facebook, com base nos postulados teóricos do caos/complexidade aplicados no contexto social. $\mathrm{O}$ estudo apontou que as práticas sociais realizadas nas infovias e nas ruas foram complementares para o processo de mobilização dos manifestantes, contribuindo assim, para a instauração de um sistema ainda mais complexo e dinâmico.

Palavras-chave: Linguagem. Manifestações sociais. Facebook. Caos/complexidade

Abstract: Electronic social networks are constitutive of contemporary social practices and are configured in important spaces of historical, cultural, ideological, psychological, linguistic, aesthetic significances for the subjects. The networks are complex and dynamic spaces and dependent on language practices in all its forms and plasticity. So, to give visibility to these running and effects, we take for analysis and reflection the discursive immaterialities that emerged from the popular manifestations of June 2013 in Brazil, in the context of Facebook, based on theoretical postulates of chaos / complexity applied in the social context. The study showed that social practices carried out on highways and streets were complementary to the mobilization process of protesters, thus contributing to the establishment of an even more complex and dynamic system.

Keywords: Language. Social manifestations. Facebook. Chaos/complexity

\footnotetext{
* Parte das reflexões apresentadas nesse artigo foi publicada nos Anais do IX Congresso Internacional da ABRALIN, ocorrido no período de 25 a 28/02/15, na UFPA, na cidade de Belém do Pará.

${ }^{1}$ Professor titular do curso de Letras e do PPGL UNEMAT/Cáceres. E-mail: ollule4@yahoo.com. Endereço: Departamento de Letras/UNEMAT/Cáceres - Av. São João, s/no - Cavalhada - CEP 78200-000. Cáceres/MT.

2 Acadêmico do curso de Licenciatura em Letras da UNEMAT/Cáceres-MT, bolsista PIBID/Inglês e bolsista voluntário da Iniciação Científica. E-mail: rodrigosantana.unemat@gmail.com. Endereço: Departamento de Letras/UNEMAT/Cáceres - Av. São João, s/nº - Cavalhada - CEP 78200-000. Cáceres/MT.
} 


\section{Introdução}

Neste artigo nos propomos a apresentar um estudo sobre o papel da rede social Facebook para a dinâmica complexa que marcou as manifestações de junho de 2013 no Brasil, a partir dos postulados conceituais da teoria do caos/complexidade. Para tanto, tomamos para análise o cartaz com o enunciado SAÍMOS DO $\underline{\text { FACEBOOK}}$, empunhado por um jovem. Em termos da Teoria do Caos, nos interessa verificar quais foram as condições iniciais que tornaram sensíveis todos os sujeitos que direta e indiretamente se posicionaram politicamente com seus gestos, tanto no contexto do Facebook como nas ruas do país e nas de outros países ao redor do mundo. Antes de focarmos na discussão aqui proposta, torna-se pertinente tecer algumas considerações sobre o termo rede social.

A ideia de rede social começou a ser usada há cerca de um século atrás com o propósito de designar um conjunto complexo de relações entre membros de um sistema social em diferentes dimensões, desde a interpessoal à internacional. Porém, no contexto da sociedade contemporânea, rede social tornou-se um termo massificado em virtude da emergência dos sistemas digitais da informação e da comunicação atualmente disponíveis no contexto da internet e das diferentes plataformas eletrônicas, tais como, computadores (PCs), notebooks, tablets e os smartphones. Esta perspectiva metálica das redes sociais confere a elas novos significados em virtude do papel que elas desempenham nas práticas socioculturais de mundo cada vez mais interconectado.

Silva (2008) argumenta que as redes sociais eletrônicas são inerentemente redes complexas e dinâmicas, uma vez que sua estrutura está em constante mutação, em função das interações entre suas partes e, nesse processo, tanto pode se modificar quanto modificar o todo em que as partes se encontram inseridas, possibilitando assim, a emergência de novos estados organizacionais no sistema. Nesta direção, Rocha (2005, p.1) diz que rede social se configura em uma estrutura auto-organizacional, pois o fato de estarem interligados entre si:

[...] permitem a união, a comutação, a troca, a transformação. Estar em rede é uma das condições de possibilidade de nossa convivência neste mundo, dada a necessidade da contínua constituição de grupos comuns em limitados espaços e simultâneos tempos.

Nesta perspectiva complexa, tornam-se pertinentes as palavras de Waldrop (1992) quando diz que a complexidade só pode existir se tanto a ordem quanto a 
desordem estiverem presentes em um sistema, uma vez que são esses aspectos contraditórios que devem co-existir em proporções equilibradas, de modo que não tornem o sistema perfeitamente ordenado, nem completamente desordenado, a ponto de não existir uma estrutura delimitada. Como procuraremos mostrar, as redes sociais eletrônicas se comportam nessa perspectiva dinâmica e altamente complexa.

No contexto deste estudo, o nível de complexidade atingido pelas discussões e interações no contexto das redes sociais sobre o preço das passagens do transporte coletivo em todo o país pode ser verificado no site Causa Brasil. Trata-se de um sistema (plataforma) abastecido automaticamente de hora em hora, por milhares de menções espontâneas que categoriza, agrupa e interpreta "a voz dos usuários manifestantes" do Facebook, Twitter, Instagram, YouTube e Google+ sobre diferentes causas sociais.

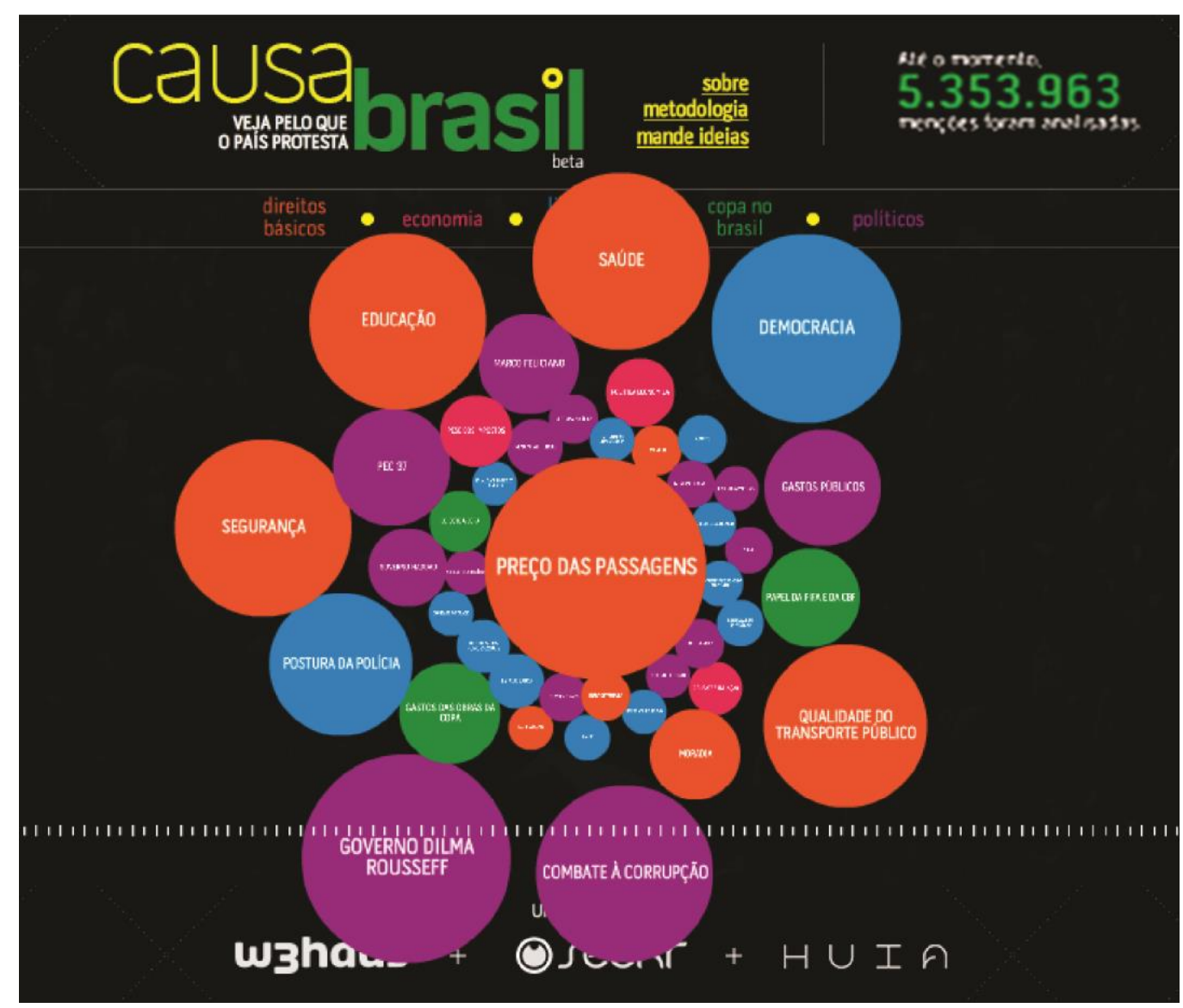

Figura 1 - Site Causa Brasil ${ }^{3}$

Conforme Figura 1, a porcentagem de cada causa é referente ao número acumulado de menções no período de 24 horas, com base em uma lista de termos

\footnotetext{
${ }^{3}$ Disponível em: http://www.causabrasil.com.br/
} 
previamente definidos, como, por exemplo: \#20centavos, \#contraoaumento, \#copapraquem, \#manifestacao, \#nãoéapenas20centavos, \#ogiganteacordou, \#vamosarua, entre outros, denominados hashtags.

As hashtags, conforme aponta Barbosa et al. (2013), representam e agrupam mensagens que podem expressar sentimentos. São metadados que podem ser utilizado como insumo para "treinar" algoritmos que visam detectar e monitorar automaticamente a opinião das pessoas no contexto dos softwares de interações sociais online. As hashtags, por este motivo, podem ser vistas como "termômetros" da opinião popular sobre um grande acontecimento mundial, como é o caso das manifestações aqui discutidas. Em termos linguísticos, as hashtags configuram-se em unidades discursivas (textos) de diferentes tipos de representações simbólicas e, consequentemente, de diferentes posições dos sujeitos inscritos no contexto das manifestaçõeshashtags.

Este movimento se torna visível na Figura 1, pois aponta o estado de monitoramento do site Causa Brasil dos dias 16 e 17/06/2013 sobre as manifestações na internet. Nela podemos verificar que o sistema havia realizado 5.353 .963 análise das menções (hashtags) feitas nas redes sociais. De cor laranja temos a causa: Preço das Passagens com 27,66\% das menções, seguidas da causa: Democracia, em azul, com 15,43\% das menções e em terceiro, também em azul, a causa: Postura da Polícia, com 9,57\% das menções.

Estes aspectos tornam visível a natureza sempre latente das redes sociais enquanto sistemas dinâmicos. Isto é sempre da ordem do instável, em decorrência dos processos em diferentes escalas e níveis de complexidade (internas ou externas). É nesta direção que, nas seções que seguem, procuraremos refletir.

\section{1 - Sensibilidade às Condições Iniciais: Efeito Borboleta}

Conforme aponta Lorenz (1963), os sistemas dinâmicos são marcados pela imprevisibilidade por serem hipersensíveis às condições iniciais, ou seja, são sistemas de dinamicidade tal, que torna impossível prever os seus comportamentos futuros. São sistemas que têm a estabilidade - equilíbrio - afetada por pequenas perturbações. Em outros termos, são sistemas sujeitos ao Efeito Borboleta ${ }^{4}$ (GLEICK, 1989), como ficou popularmente conhecida a Teoria do Caos. Estes sistemas têm comportamento inverso

\footnotetext{
4 "O bater de asas de uma borboleta no Brasil pode desencadear um tornado no Texas" 
aos tidos como perfeitamente regulares, ou seja, aqueles que permitem saber com exatidão seus comportamentos futuros, independentemente do tempo de verificação.

Nesta direção, podemos perguntar: Qual ou quais foram as condições iniciais que, em seus efeitos, tornaram o sistema das manifestações nas redes sociais e nas ruas algo tão dinâmico? Tomaremos, para efeito deste artigo, como condição inicial o valor do aumento defendido pela Prefeitura de São Paulo para a tarifa dos ônibus e metrôs: 0,20 centavos, embora saibamos que não seja uma tarefa fácil determinar com exatidão as reais condições iniciais do movimento, pois teríamos de considerar variáveis que nos escapam por envolverem uma multiplicidade de aspectos de natureza social, política, cultural, econômica, ideológica, psicológica, mercadológica, etc,

Os 0,20 centavos de reais elevava o preço das passagens de 3,00, para 3,20 reais. $\mathrm{Na}$ perspectiva da Teoria do Caos, os 0,20 centavos se configuraram nas condições iniciais - Efeito Borboleta - do movimento como um todo, pois foi esse valor que marcou o inicio da trajetória do sistema imprevisível e caótico do sistema dinâmico das manifestações e que tornaram difíceis à época - e ainda hoje - prever os seus resultados finais. 


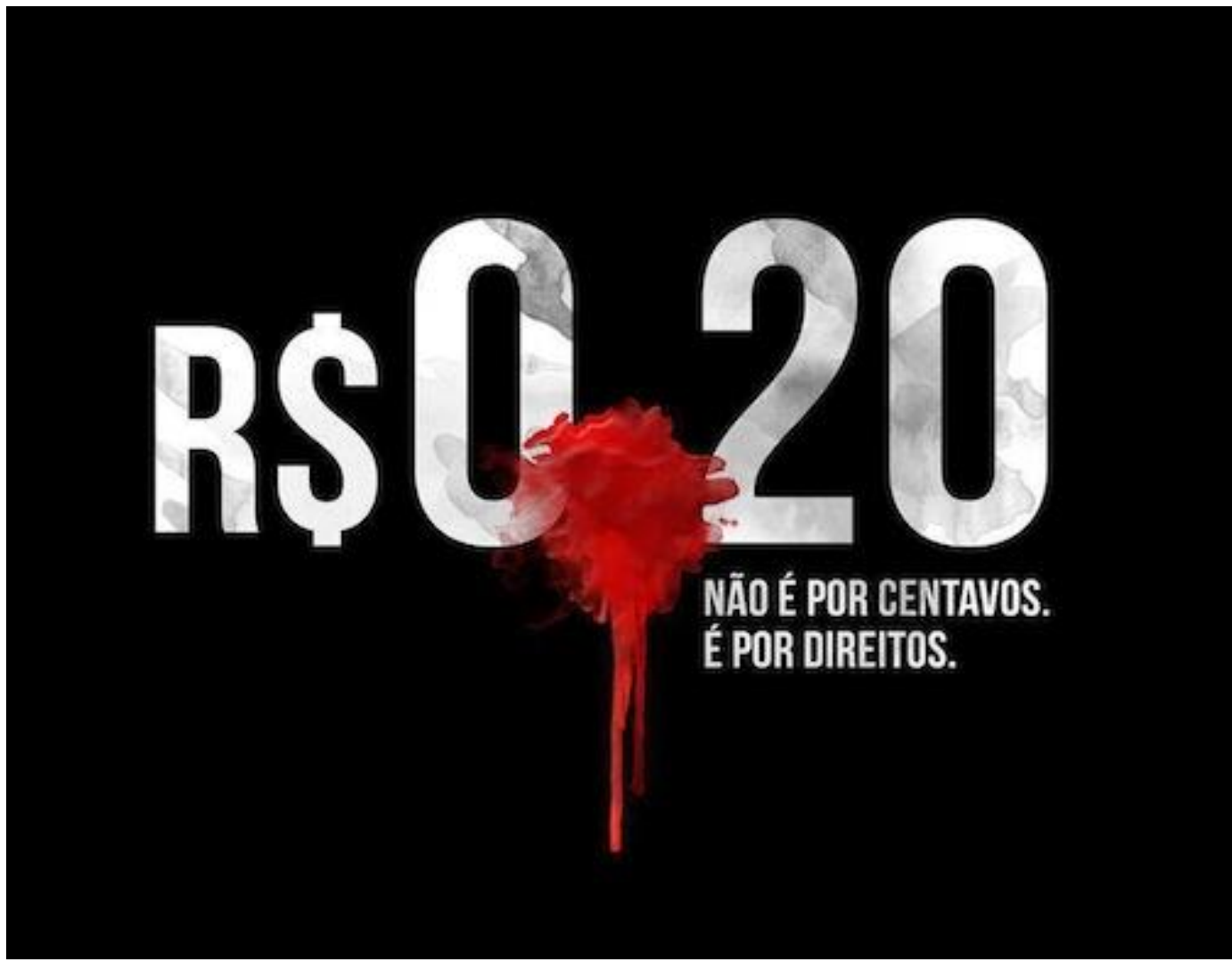

Figura 2 - Site Pragmatismo Político 5

Movidos pelo interesse em ter suas reivindicações atendidas pelos setores políticos e econômicos de São Paulo e das demais cidades do país, teve inicio, no contexto da internet, por meio das redes sociais, em particular o Facebook, um ciclo elevadíssimo de manifestações por meio de mensagens, vídeos, memes, fotos, etc. que impulsionou grande parte da população do país - jovens, na sua maioria - a se informarem e se posicionarem de forma contundente e irreversível no contexto desterritorializado da internet. Podemos dizer que o movimento foi viral, pois muitas pessoas, em certa medida, já estavam contaminadas e com o passar dos dias o grau de virulência assumiu proporções nunca vistas no país, consequentemente, imprevisíveis.

Para Gleick (1987) e Waldrop (1992) são sistemas que estão à beira do caos em decorrência dos níveis de turbulência que o sistema começa a apresentar, ou seja, comportamentos que possibilitam a criação de um tipo especial de equilíbrio entre ordem e o caos. Para Waldrop (1993, p. 12), trata-se de uma fase de máxima criatividade em que o sistema opera entre a ordem e a aleatoriedade do caos. Para o

\footnotetext{
5 Disponível em: http://www.pragmatismopolitico.com.br/2013/06/nao-e-sobre-20-centavosestupido.html
} 
autor, a beira do caos é "a zona de batalha em constante alternância entre a estagnação e a anarquia, o ponto onde um sistema complexo pode ser espontâneo, criativo, e vivo".

Neste sentido, são pertinentes as observações de Ockerman (apud PAIVA, 2009) quando diz:

\begin{abstract}
[a] beira do caos é um estado paradoxal, um acaso em espiral entre a ordem e o caos, uma oscilação ativa entre dois extremos, caracterizada pelo risco, pela exploração, e pela experimentação. É aqui que o sistema opera no seu mais alto nível de funcionamento, onde acontece o processamento de informação, onde se correm riscos e onde se experimenta novo comportamento. Dizemos que uma mudança é inovadora e que o sistema aprendeu e evoluiu quando um novo comportamento emerge e quando a função primária e as regras de operação do sistema são modificadas de tal forma que seus níveis de adaptação são aperfeiçoados a partir da relação com outros sistemas.
\end{abstract}

Como podemos perceber nas palavras de Gleick, Waldrop e de forma mais contundente em Ockerman, o termo que expressa essa dinâmica está relacionado com processos adaptativos. Os movimentos de ordem/desordem/ordem constitutivos de um sistema dinâmico seriam fases de adaptação do sistema, independente de tempo de duração de cada uma das fases e do espaço em que ocorrem.

Nesta direção, é interessante a observação de Colom (2004) quando diz que o resultado da ordem interna é o caos do conjunto que se auto-organiza em formas ordenadas e que rapidamente se desordena para formar outras ordens, às quais, sucessivamente, se seguirão novas desordens propiciadoras de outras novas ordens.

\title{
2 - Das infovias de bits às vias de asfalto
}

Em meio à profusão de cartazes coloridos e com diferentes enunciados de protestos escritos a mão em papel cartolina, um cartaz nos chamou a atenção. Trata-se do cartaz Saímos do Facebook, como é possível de se verificar na Figura 3. 


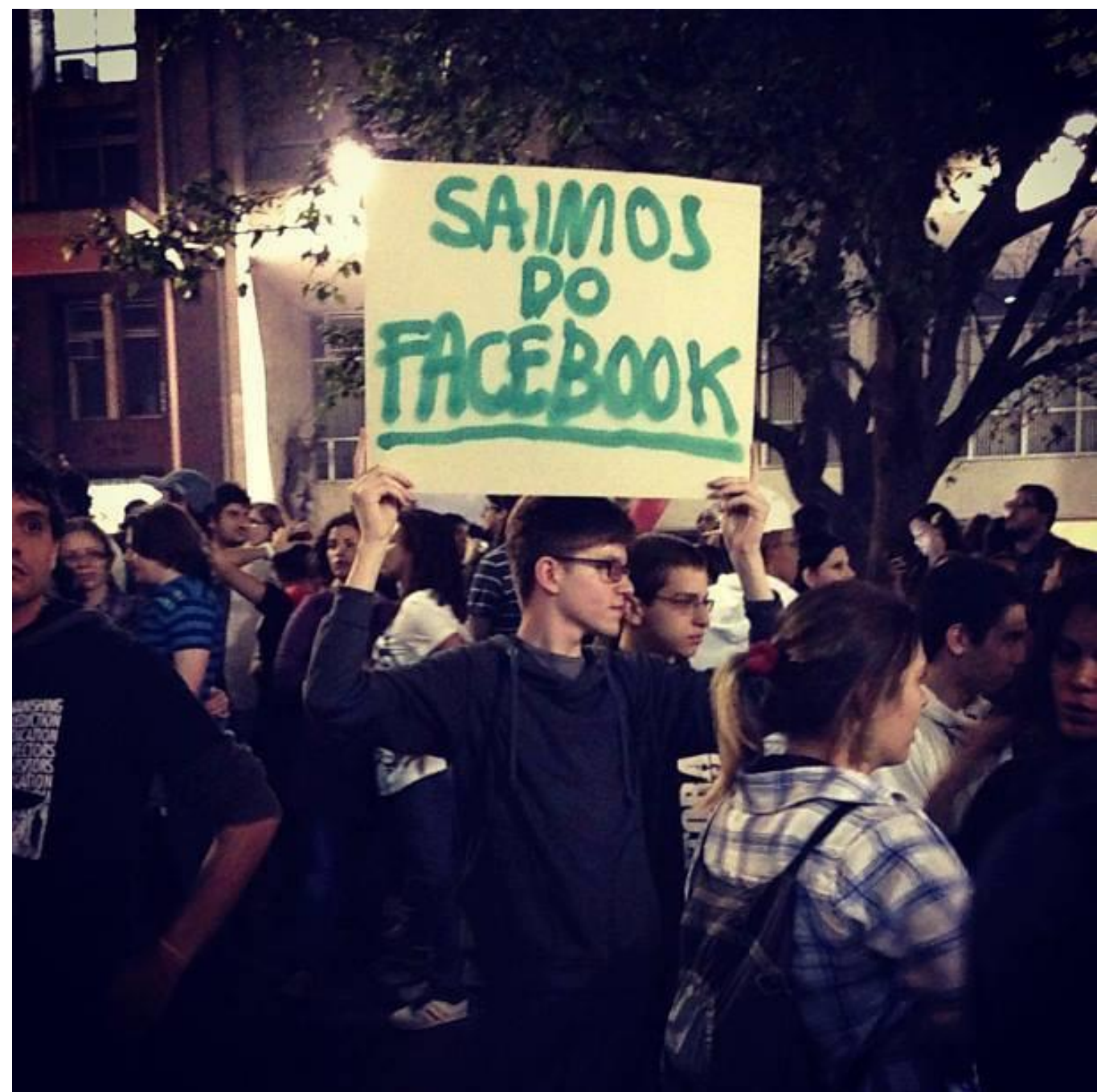

Figura 3 - Site Manchete Atual ${ }^{6}$

Saímos do Facebook é um enunciado emblemático, pois dá visibilidade a uma série de interpretações relacionadas direta e indiretamente com questões contemporâneas, particularmente as decorrentes das tecnologias digitais, como casos é o caso das redes sociais eletrônicas. Em outros termos, todas as manifestações que se materializavam através dos milhares de perfis do Facebook e que percorriam as infovias da internet, bifurcavam-se também para as vias públicas das cidades, para então retornarem novamente para o contexto eletrônico. É como se existisse uma única grande via de mão dupla que unia o mundo virtual e o real e por onde passavam milhares e milhares de manifestações com suas vozes ampliadas e reverberadas dinamicamente em todos os cantos do país e também do mundo. Uma via feita ora de bits ora de asfalto, pedras, concreto, terra. Um espaço público onde a linguagem, em todas as suas

\footnotetext{
${ }^{6}$ Disponível em: http://mancheteatual.com.br/site-faz-compilacao-de-abusos-policiais-cometidos-durantemanifestacao-em-sao-paulo
} 
modalidades (verbais e não-verbais), se moldava plasticamente e se materializava, com vistas à produção de sentidos, por meio de imagens, vídeos, mensagens escritas, mas também de papéis, panos, plásticos, roupas, acessórios, etc.

Na frase Saímos do Facebook, a palavra saímos é derivada do verbo regular sair e expressa o tempo presente e o pretérito perfeito do modo indicativo para a primeira pessoa do plural (nós). Sair, conforme o dicionário Houaiss (2001, p. 2497), apresenta uma série de significados. Dentre eles destacamos os seguintes:

1. Passar do interior para o exterior; 2. Deixar um local, uma morada, um pouso e seus ocupantes; conhecer pessoas, entreterse; 3 manter relacionamento de companheirismo, amoroso ou erótico (com); frequentar-se, ver-se; 4 passar para o outro lado de (algo), por cima ou através de; atravessar, cruzar; 5 ir para fora de (falando de coisas); 6. Fazer-se visível na totalidade ou parcialmente; 7 deixar o lugar em que se está, com destino determinado ou não; 8. Aparecer ou pôr-se diante de alguém, para enfrentá-lo ou embaraçá-lo; 9 deixar de estar em determinado lugar, em certo estado, deixar de fazer tal coisa etc.; 10. Deixar (o lugar onde se estava); 11. Ir para fora do seu lugar precípuo ou do que o continha (falando de coisas que devem ali se manter); 12. Encontrar-se em (determinado estado ou condição) depois de (determinada experiência); 13. Começar um novo período ou uma nova época; mudar de estado ou posição; 14. Transcorrer (como um todo); decorrer, desenrolar-se, desenvolver-se. (Grifos nossos)

Todos os significados dicionarizados de sair, como podemos verificar, remetem a uma dinâmica de movência de um espaço para o outro. Por outro lado, chama a atenção também para a acepção que remete a uma posição de resistência, como se pode verificar nas definições em destaque no Houaiss.

Outro aspecto expresso no enunciado Saímos do Facebook refere-se ao fato da palavra Facebook estar sublinhada no cartaz. Podemos dizer que não se trata de uma alegoria do cartaz, mas sim uma ação refletida para chamar a atenção dos leitores do cartaz para algo que se quer enfatizar, acentuar, enfim, conferir uma inflexão especial da voz marcada no escrito. Ou seja, o autor quer dar visibilidade - GRITANDO - e mostrar de forma inequívoca o lugar de onde saíram para tomar as ruas: das redes sociais. Tratase, pois, de uma estratégia linguística que expressa a dinâmica que nos permite pensar também na desconstrução de um entendimento equivocado de que as pessoas por trás de seus computadores, tablets, smartphones e dentro da internet são pessoas alienadas da realidade das coisas da sociedade e da cultura do mundo físico. Na verdade, estes nativos e emigrantes digitais (PRENSKY, 2014), estão na interface do mundo real. 
Movem-se com desenvoltura entre os dois mundos que conformam a realidade contemporânea, a qual ainda pouco entendemos e que por esta razão, não é compreendida. Não podemos apagar o que já é constitutivo de uma parcela considerável da sociedade. Ela é a vanguarda do mundo contemporâneo altamente conectado.

As dinâmicas relacionadas às manifestações de julho de 2013, virtuais ou reais, se configuram como um sistema altamente complexo, não-linear, aberto, imprevisível, sensível às condições iniciais, bifurcativos e adaptativos.

Pigott (2012, p. 353) aponta, reverberando o entendimento de outros estudiosos da complexidade, que:

\footnotetext{
Sistemas complexos são complexos porque consistem de "múltiplas interações entre muitos componentes diferentes" (Rind, 1999, p. 105), cada variável é um jogador mais ou menos significativo em uma rede interconectada de influências interativas. Eles são não-lineares no sentido de que uma perturbação do sistema pode causar um efeito significativo e desproporcional, um efeito proporcional ou um efeito insignificantemente desproporcional (tradução nossa).
}

Neste sentido, tomaremos a rede social, Facebook, como um Sistema Adaptativo Complexo (SACs). Conceito formulado por Holland (1995), os SACs referem-se aos sistemas que são capazes de se autoconfigurarem para se adaptarem às características correntes do processo ou do ambiente em que estão inseridos, ou seja, sistemas que atingem a solução através de sucessivos ajustes e interações. Em outros termos, nos SACs torna-se contraditória a vigência da dinâmica centralizadora e hierarquizada, uma vez que não se tem apenas um sujeito dinamizador, mas um conjunto deles e todos estão aptos para contribuir na solução de um problema, compartilhar informações ou conhecimentos de interesse da rede, marcado pelo contraditório. Um SAC tem duas características importantes: a diversidade (HOLLAND, 1995; VAN LIER, 2004) e a redundância (DAVIS e SUMARA, 2006), em decorrência de fatores relacionados os próprios sujeitos (bio-psico-social) e também fenômenos externos (os outros, as condições de produção, etc.) que provocam a evolução e a dinâmica complexa da rede social, tanto em suas partes como em seu todo sistêmico.

Quanto maior a diversidade da rede, maiores são as chances de o sistema possuir redundância em sua dinâmica. A redundância, conforme apontam Davis e Sumara (2006), refere-se à capacidade dos sujeitos, enquanto agentes do sistema, substituírem funcionalmente o outro em situação de desestabilização do sistema, ou seja, um dos sujeitos assume, ainda que momentaneamente, a dianteira do processo, e pode, com 
isso, reorganizar o sistema. Conforme Silva (2008), trata-se de uma assunção espontânea e, portanto, imprevisível como mecanismo de manutenção da estabilidade do sistema que conforma a rede social. Os SACs, nesta direção, abrigam em seu interior uma inteligência distribuída, que, conforme Levy (1998), configura-se em "uma inteligência distribuída por toda parte do sistema, incessantemente valorizada, coordenada em tempo real, que resulta em uma mobilização efetiva das competências".

\section{As bifurcações das manifestações}

Conceito formulado por Prigogine (1988), a bifurcação refere-se às encruzilhadas que produzem ramificações dentro de um sistema. Para o autor, trata-se de determinadas ocorrências que podem significar o fim, a origem e um novo começo do sistema. No entendimento do autor, o futuro evolutivo do sistema não está determinado, pois se encontra imerso na incerteza, aberto e em contínua construção. Ainda sobre a bifurcação, Colom (2004) diz que ela ocorre no instante em que um microfenômeno (por exemplo, um ruído) se repete de tal forma que chega a alcançar grandes magnitudes, fazendo com que o sistema mude o seu rumo evolutivo (nascimento da bifurcação). Dessa forma, segue o autor, a bifurcação se caracteriza como um processo de realimentação positiva, permitindo supor que a origem dos estados caóticos pode, mais tarde, adaptar-se a situações mais equilibradas (estabilizadas), em função da realimentação negativa que diminui ou subtrai as diferenças. Para Silva (2008, p. 48):

Um sistema pode ficar estabilizado por um número determinado de tempo até
que ocorra uma nova perturbação, como consequência de processos
iterativos, e crie uma nova bifurcação. Nessa direção, a bifurcação refere-se
ao ponto crítico do sistema, isto é, o momento que pode conduzir a
desestabilização do sistema e, no decorrer do tempo, gerar um novo tipo de
ordem. As possibilidades das ramificações ou bifurcações apresentam uma
variedade de opções de comportamento e, devido ao seu grau de liberdade, o
sistema pode apresentar também uma multiplicidade de escolha, tendo,
assim, as mais diferentes possibilidades de se auto-organizar.

A relação do conceito de bifurcações com as manifestações está exatamente nos compartilhamentos, independentemente dos sentidos que produzem nos sujeitos. Podemos tomar como exemplo as informações e reflexões realizadas anteriormente com base nos dados fornecidos pelo site Causa Brasil. Cada informação que é lançada na rede por um perfil público no Facebook é acessada pelo número de amigos que esse perfil possui. As bifurcações podem ocorrer, então, no momento em que um post é publicado e compartilhado milhares e milhares de vezes entre os participantes da rede. 
Quando temos uma postagem realizada por determinado perfil em seu mural, um número $\mathrm{x}$ de outros perfis que tem acesso a ele recebe essa postagem em seu feed de notícias imediatamente. No momento em que há o compartilhamento desta postagem por outro perfil, naturalmente o número de pessoas que tem acesso a esse conteúdo se multiplica de acordo com as variáveis. Essas variáveis referem-se ao número de amigos adicionado a cada perfil. Um exemplo desta dinâmica bifurcativa, em termos numéricos, pode ser verificado no vídeo publicado no YouTube, intitulado "Policial quebra vidro da própria viatura", publicado no dia 13/06/2013.

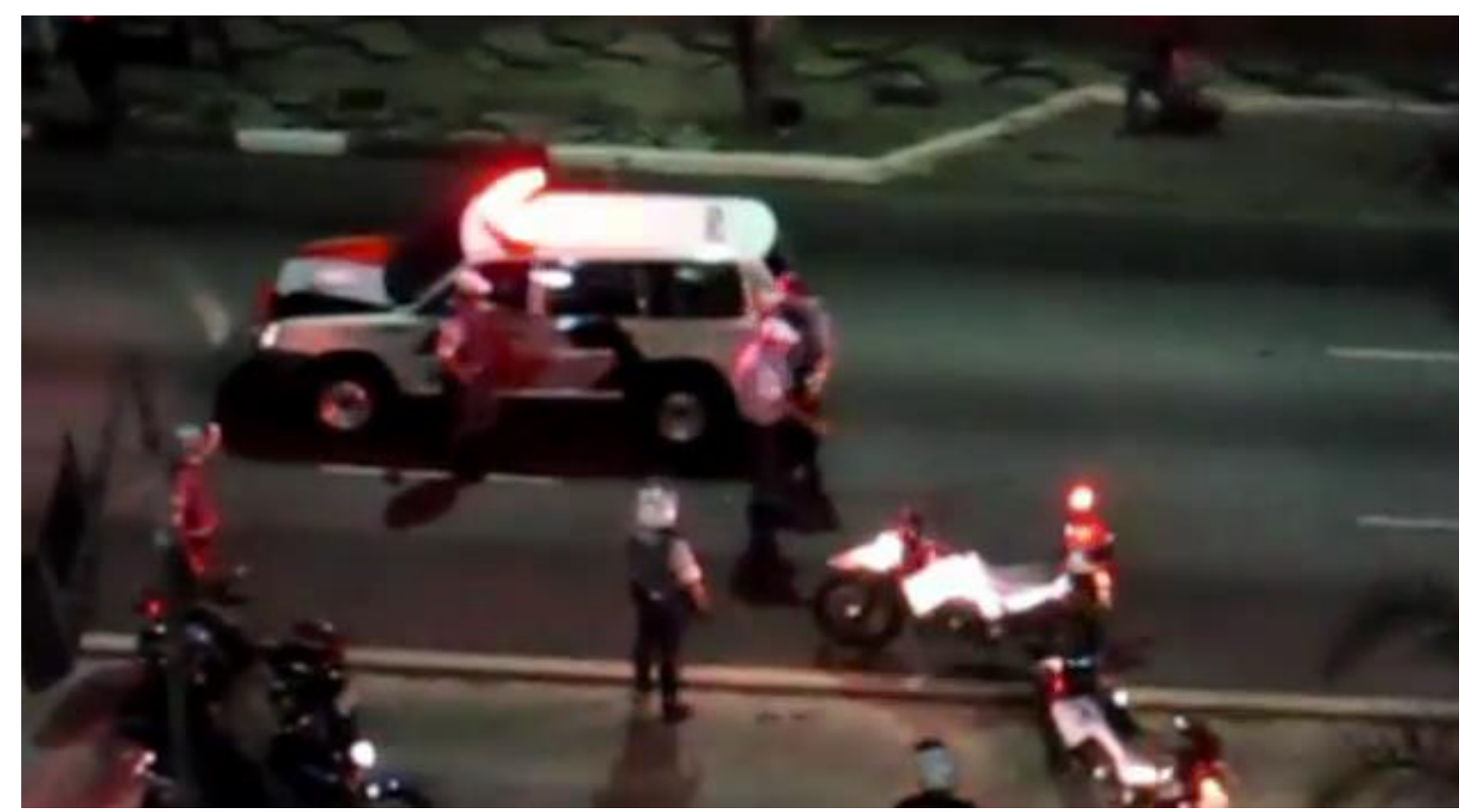

Figura 4 - Site YouTube

Este vídeo, até a data em que foi analisado, teve 2.333 .783 de visualizações, um número extremamente expressivo no contexto do Youtube, e gerou 8.302 comentários (contra e a favor) e o mais importante para a reflexão sobre bifurcação, o vídeo foi compartilhado por 6.795 pessoas, nos mais diferentes sistemas, em particular no Facebook.

Briggs e Peat (1999) dizem que cada decisão tomada em um determinado momento da ramificação implica a ampliação de algo pequeno (microfenômeno). Dessa forma, ainda que a causalidade aja em cada instante, as ramificações acontecem imprevisivelmente e, nesse processo, podem possibilitar a emergência de sistemas que apresentam autoreferenciações, ou seja, fractais.

\footnotetext{
${ }^{7}$ Disponível em: https://www.youtube.com/watch?v=i6PKTTgFq3Q 


\section{Atrator estranho: as marcas do caos}

Para terminar estas conceitualizações sobre os sistemas dinâmicos aplicados metaforicamente nestas reflexões sobre as dinâmicas complexas das manifestações no Brasil, apresentaremos o conceito caótico denominado atrator estranho. Formulado por Takens e Ruelle (1971), o atrator estranho diz respeito a um ponto para onde todas as trajetórias do sistema são conduzidas. Em outras palavras, trata-se da posição preferida pelo sistema. Caso haja outra posição inicial, o sistema evoluirá em direção ao atrator localizado nessa posição e, não havendo maiores interferências de forças externas, a trajetória do sistema ficará circunscrita aos limites do atrator seja ele pontual ou periódico. $\mathrm{O}$ atrator pontual refere-se aos sistemas, cujas dinâmicas sempre tenderão a girar em torno de um único ponto, já o periódico apresenta um padrão cíclico, ou seja, oscila entre certo número de estados fixos. É a natureza dispersiva dos atratores no sistema que provoca a turbulência de um sistema e, consequentemente, seu caráter nãolinear. Ruelle (1993) diz que os atratores estranhos têm um aspecto estranho e estão relacionados ao fenômeno de dependência hipersensível das condições iniciais (Lorenz, 1996). Para Colom (2004), a evolução e as constantes mudanças de estado dos sistemas caóticos jamais são idênticas porque esses sistemas obedecem a atratores estranhos que são os causadores das condutas imprevistas - tipicamente caóticas. É uma modalidade de atrator que comporta a idéia de ser um fenômeno relacionado com os estados turbulentos de um sistema que pode conduzir ao caos e, paradoxalmente, também funciona como um auto-organizador do caos, conforme defendem vários autores, dentre eles Briggs e Peat (1999).

Senge (1990) e Wheatley (1999) dizem que a recorrência dos atratores estranhos podem ser estruturais e/ou comportamentais, isto é, eles podem apresentar padrões de forma e/ou função que influenciam e são fortemente influenciados pela dinâmica interna do sistema.

Essas considerações metafóricas sobre o conceito de atrator estranho, quando transpostas para o contexto das manifestações reais ou virtuais podem ser referenciadas em dois eventos distintos: a atuação policial e a dos blackblocs (Figura 5). 


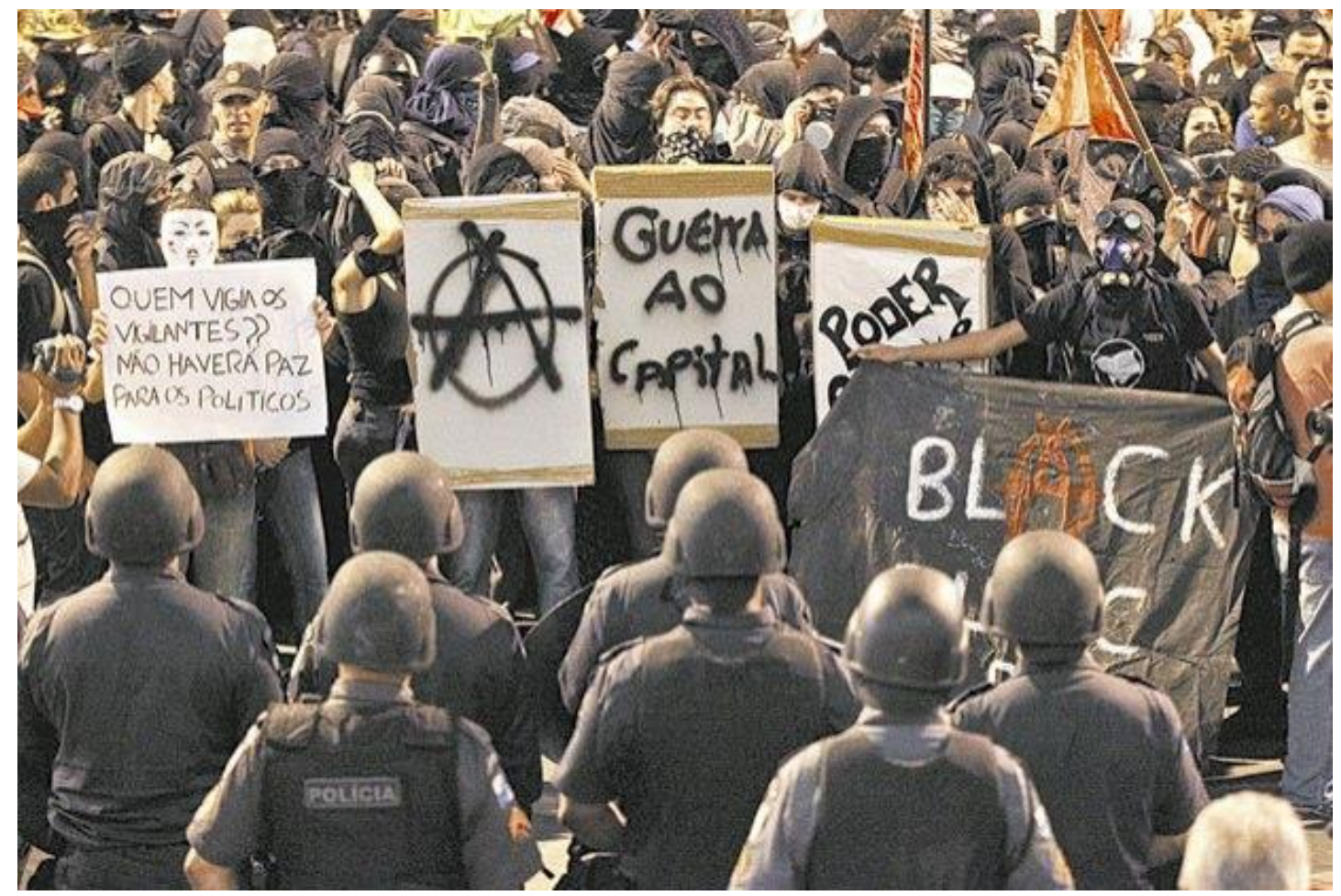

Figura 5 - Site Pragmatismo Político ${ }^{8}$

Como discutido anteriormente, as redes sociais, como o caso do Facebook, tiveram papeis decisivos para a emergência das manifestações no Brasil. Toda a organização para as manifestações nas ruas teve suas condições inicias dentro das redes sociais. Foram elas, em particular, que mobilizaram os milhões de manifestantes pelo Brasil afora. Apesar de toda a dinâmica complexa dentro das redes e nas ruas, o sistema das manifestações apresentava em suas partes e em seu todo, uma ordem. Eram passeatas de protestos relativamente pacíficas feitas por pessoas de todas as classes e idades da sociedade. Apesar de alguns episódios isolados de maior turbulência em meio às pessoas, tais fenômenos não perturbavam a ordem da dinâmica das manifestações. Podemos dizer que o atrator era periódico, pois apresenta um padrão cíclico, ou seja, oscila entre certo número de estados fixos, podemos dizer entre os sistemas da rede e os da rua.

Apesar de não termos a intenção de fazermos aqui nenhum juízo de valor sobre a atuação da polícia e dos blackblocs durante as manifestações, podemos assegurar que estes dois fenômenos configuram-se em dois exemplos de atratores estranhos imprevisíveis - pois não se esperava uma atuação tão violenta por parte dos policiais e também dos blackblocs. Esses dois comportamentos atratores mudaram totalmente e de

\footnotetext{
${ }^{8}$ Disponível em: http://www.pragmatismopolitico.com.br/2014/06/black-blocs-pcc-e-o-problema-de-lermanchete.html
} 
forma irreversível a rota do sistema, pois muitas das milhares de pessoas, com medo e se sentido inseguras esvaziaram as ruas. A violência nas ruas alimentou os protestos "seguros" nas redes sociais. Esta situação nos remete a Colom (2004) quando diz que o resultado da ordem interna é o caos do conjunto que se auto-organiza em formas ordenadas e que rapidamente se desordena para formar outras ordens, às quais, sucessivamente, se seguirão novas desordens propiciadoras de outras novas ordens.

\section{Considerações Finais}

Para este trabalho tomamos o cartaz Saímos do Facebook como ponto de partida de estudo para uma melhor compreensão da dinâmica complexa das redes sociais e seus efeitos para as manifestações populares ocorridas no Brasil em junho de 2013. Nesse sentido, o Facebook foi a rede social delimitada por nós, em virtude de sua popularidade e, claro, seu papel nas manifestações. Toda a reflexão foi norteada com base nos conceitos dos denominados sistemas dinâmicos, ou seja, sensibilidade às condições iniciais (Efeito Borboleta), bifurcação e atrator estranho.

$\mathrm{O}$ estudo possibilitou, em primeiro lugar, perceber que o Facebook enquanto rede social configura-se em um espaço de práticas sociais contemporâneas onde as pessoas se inscrevem para compartilharem objetivos comuns. No entanto, é preciso ressaltar que apesar de suas semelhanças elas guardam traços bastante distintos. Por exemplo, no contexto virtual as redes sociais apresentam um comportamento típico dos Sistemas Adaptativos Complexos, pois podem constantemente se auto-configurarem e se adaptarem às novas realidades, em decorrência da diversidade (HOLLAND, 1997; VAN LIER, 2004) e a redundância (DAVIS e SUMARA, 2006) que conformam suas estruturas, pois elas abrigam em seu interior inteligências distribuídas (LEVY, 1998), que incessantemente mudam e provocam novos formatos, em decorrência do que os sujeitos provocam, quando, por exemplo, postam suas mensagens, seus vídeos, suas fotos, etc.

Outra questão possibilitada por essa reflexão diz respeito ao entendimento de que, definitivamente, a visão dicotômica entre virtual e real não se sustenta mais. Na contemporaneidade, o mundo real e o mundo virtual estão cada vez mais imbricados, conformando assim, uma realidade mista (HANSEN, 2006), cada vez mais complexa e dinâmica. No contexto desse trabalho, o que os sujeitos produziram na rede social Facebook foi tão real quanto aquilo que produziram nas ruas, praças, cidades, etc. O que temos, então, são tão somente espaços diferentes de práticas sociais e de produção de 
linguagem extremamente reais. Assim, podemos dizer que, ao mesmo tempo em que se enuncia que Saímos do Facebook [para as ruas das cidades], torna-se possível, dizer então: Saímos das Ruas [para o Facebook e para todos os outros sistemas de interação social da cibercultura). Por fim, corroborando o que muitos pesquisadores da área da Linguística Aplicada, tais como Larsen-Freeman, 1997; Paiva, 2002; van Lier, 2004; Lantolf, 2006; Cameron e Deignan, 2006, entre outros, vêm sustentando, a teoria do caos/complexidade se apresenta em uma proposição teórico-metodológica bastante pertinente, enquanto metáforas, para melhor descrevermos e compreendermos os sistemas dinâmicos das práticas sociais no mundo contemporâneo.

\section{Referências}

ASSMANN, Hugo. Metáforas novas para reencontrar a educação. São Paulo: Unimep, 1998.

BARBOSA, G. A. R. et al. Caracterização do uso de hashtags do Twitter para mensurar o sentimento da população online: Um estudo de caso nas Eleições Presidenciais dos EUA em 2012. Simpósio Brasileiro de Banco de Dados: Recife, $2013 . \quad$ Disponível em http://sbbd2013.cin.ufpe.br/Proceedings/artigos/pdfs/sbbd_shp_19.pdf. Acesso em 03/04/14

BRIGGS, J. e PEAT, F. D. Seven life lessons of chaos. Harper Collins, New York, 1999.

CAMERON, L. e DEIGMAN, A. The emergence of metaphor in discourse. Applied Linguistics 27/4: 671 - 690 _ Oxford University Press 2006.

CAPRA, F.. Vivendo Redes. In: Duarte, Fábio: Quandt, Carlos; Souza. Queila. O Tempo Das Redes. Editora Perspectiva, 2008.

CARDOSO, Clodoaldo. A canção da inteireza: uma visão holística da educação. São Paulo: Summus, 1995.

COLOM, A. J. A (des)construção do conhecimento pedagógico: novas perspectivas para a educação. Porto Alegre: Artmed, 2004.

D’AMBRÓSIO, Ubiratan. Etnomatemática. São Paulo: Editora Ática, 1993.

DAVIS, B. e SUMARA, D. Complexity and education: inquires into learning, teaching and research. Mahwah, New Jersey \& London, Lawrence Erlbaum Associates, 2006.

FISCHER, Steven Roger. Uma breve história da linguagem. tradução Flávia Coimbra.- Osasco, SP: Novo Século Editora, 2009.

FREEMAN, Linton. The Development of Social Network Analysis. Vancouver: Empirical Press, 2006.

GLEICK, J. Caos: a criação de uma nova ciência - Rio de Janeiro: Campus, 1989.

HANSEN, M.. Bodies in Code. New York, Routledge, 2006. 
HOLLAND, J. H. Hidden Ordem: how adaptation builds complexity. Perseus books, Cambridge, Massachusetts, 1997.

HOUAISS, Antônio. VILLAR, Mauro de Salles. Grande Dicionário Houaiss da Língua Portuguesa. Rio de Janeiro: Objetiva, 2001.

HP. O que são redes sociais. Acesso dia 26/09/2013. Disponível em: http://h30458.www3.hp.com/br/ptb/smb/941786.html.

KUHN, Thomas. A estrutura das revoluções científicas. $16^{\circ}$. ed. São Paulo: Perspectiva, 2001.

LAKOFF, G. e TURNER, M. More than cool reason: a field guide to poetic metaphor. USA, The University of Chicago, 1989LANTOLF, J. P. Language Emergence: implications for applied linguistics - A social perspective. 27/4: 671 - 690 _ Oxford University Press 2006.

LARA, Thiago Adão. Caminhos da razão no ocidente: a filosofia ocidental do renascimento aos nossos dias. 4. ed. Petrópolis: Vozes, 1991.

LARSEN-FREEMAN, D. Chaos/complexity science and second language acquisition. Applied Linguistics. Oxford: Oxford University Press, v.2, n. 18, 1997.

LEVY, P. A Inteligência Coletiva por uma antropologia do ciberespaço. São Paulo: Edições Loyola, 1998.

LORENZ, E. N. Essência do caos. Brasília: Editora da Universidade de Brasília, 1996.

MORAES, Maria Cândida. O paradigma emergente. Campinas: Papirus, 1997.

MORIN, Edgar. Introdução ao Pensamento Complexo. Porto Alegre: Sulina, 2005.

Educação e complexidade: os sete saberes e outros ensaios. São Paulo: Cortez, 2002.

PAIVA, V. L. M. E. Caleidoscópio: fractais de uma oficina de ensino aprendizagem. Memorial apresentado para concurso de professor titular na Faculdade de Letras da Universidade Federal de Minas Gerais, 2002.

Caos, Complexidade e aquisição de segunda língua. In: PAIVA, V.L.M.O.; NASCIMENTO, M. (Org.) Sistemas adaptativos complexos: lingua(gem) e aprendizagem. Belo Horizonte: Faculdade de Letras/FAPEMIG, 2009. p.187-203

PIGOTT, Julian. A call for a multifaceted approach to language learning motivation research: Combining complexity, humanistic, na critical perspectives. Studies in second language learning and teaching. Volume 02 número 03. 366 p. 2012.

PINTO, Álvaro Vieira. Ciência e Existência: problemas filosóficos da pesquisa científica. Rio de Janeiro: Paz e Terra, 1979.

PRENSKY, M. Digital natives, digital immigrants. 2001. Disponível em: <http://www.marcprensky.com/writing/>. Acesso em 04/09/2014.

PRIGOGINE, I. O nascimento do tempo. Lisboa, Portugal: Edições 70, 1988.

RECUERO, Raquel. Redes sociais na internet - Porto Alegre: Sulina, 2009. (Coleção Cibercultura).

ROCHA, Cristianne Maria Farner. As redes em saúde: entre limites e possibilidades. 2005. 
http://www.ensp.fiocruz.br/observarh/arquivos/trabalho_redes1.pdf

em: 30/05/2014.

ROSNAY, J. El hombre simbiótico, Madri, Cátedra, 1996.

RUELLE, D. e TAKENS, F. On the nature of turbulence. Commun. Math. Phys., v. 20, p. 167-92, 1971; v. 23, p. 343-4, 1971.

RUELLE, D. Acaso e caos. Sao Paulo: Editora da Universidade Estadual Paulista, 1993

SENGE, M. A Quinta Disciplina: a arte e a prática da organização que aprende. Tradução: O. P. traduções. São Paulo, Best Seller, 1998.

SILVA, Valdir. A dinâmica caleidoscópica do processo de aprendizagem colaborativa: um estudo na perspectiva da complexidade/caos. Trabalho apresentado ao Programa de Pós-Graduação em Estudos Linguísticos da Faculdade de Letras da Universidade Federal de Minas Gerais, Linha J de Pesquisa: Linguagem e Tecnologia. Belo Horizonte, 2008.

VAN LIER, L. The ecology and semiotics of language learning: a sociocultural perspective. Kluwer Academic Publishers. 2004

VASCONCELlOS, Maria José Esteves. Pensamento sistêmico: novo paradigma da ciência. Campinas: Papirus, 2002.

WALDROP, M.M. Complexity: the emerging science at the edge of order and chaos. New York: Touchstone, 1992.

WHEATLEY, M. J. Leadership and the new science: Discovering order in a chaotic world. San Francisco: Berrett-Koehler Publishers. 1999. 
Para citar essa obra:

SILVA, V., SILVVA. R. S. Das infovias às ruas: O Facebook e as manifestações sociais na perspectiva da teoria do caos/complexidade. In: RUA [online]. $\mathrm{n}^{\mathrm{o}}$. 21. Volume 2, p. 285 - 302 - ISSN 1413-2109. Novembro/2015. Consultada no Portal Labeurb - Revista do Laboratório de Estudos Urbanos do Núcleo de Desenvolvimento da Criatividade. http://www.labeurb.unicamp.br/rua/

Capa: MANCHETE ATUAL. Disponível em: http://mancheteatual.com.br/site-fazcompilacao-de-abusos-policiais-cometidos-durante-manifestacao-em-sao-paulo

\section{Laboratório de Estudos Urbanos - LABEURB}

Núcleo de Desenvolvimento da Criatividade - NUDECRI

Universidade Estadual de Campinas - UNICAMP

http://www.labeurb.unicamp.br/

\section{Endereço:}

LABEURB - LABORATÓRIO DE ESTUDOS URBANOS UNICAMP/COCEN / NUDECRI

CAIXA POSTAL 6166

Campinas/SP - Brasil

CEP 13083-892

Fone/ Fax: (19) 3521-7900

Contato: http://www.labeurb.unicamp.br/contato 